\title{
INFECCIÓN PULMONAR POR Mycobacterium avium EN PACIENTE VIH/SIDA: PRIMER REPORTE EN PERÚ
}

\author{
Juan Carrasco ${ }^{1, a}$, Leslie Soto ${ }^{1,2, b}$, Frine Samalvides ${ }^{1,2, b}$, Luis Asencios ${ }^{3, c}$, \\ Neyda Quispe ${ }^{3, c}$, Eddy Valencia ${ }^{3, c}$
}

RESUMEN

El complejo Mycobacterium avium (MAC) es un patógeno que se encuentra en el medioambiente y causa infecciones tanto en pacientes inmunocompetentes como inmunocomprometidos. Se presenta el caso de un paciente VIH positivo varón de 38 años infectado por $P$. jirovecii y aparentemente infectado por Mycobacterium tuberculosis desde el año 2009, el cual fue tratado con antibioticoterapia para pneumocistosis y terapia antituberculosis (TB) logrando mejoría parcial. En el año 2012 se le realizó nuevamente examen de cultivo y un nuevo tratamiento anti TB, frente a la sospecha de estar en presencia de una cepa de TB multidrogorresistente se recomienda realizar la identificación micobacteriana. El examen de cultivo fue positivo y el resultado genotípico resultó positivo para MAC. Se reporta el primer caso de un paciente VIH/SIDA con infección pulmonar por MAC en el Perú, así como una breve revisión de los aspectos epidemiológicos, clínicos y de tratamiento.

Palabras clave: Complejo Mycobacterium avium; Infecciones por VIH; Infecciones del sistema respiratorio (fuente: DeCS BIREME)

\section{Mycobacterium avium LUNG INFECTION IN HIV/AIDS PATIENT: FIRST REPORT IN PERU}

\begin{abstract}
The Mycobacterium avium complex (MAC) is a pathogen found in the environment which causes infections in immunocompetent and immunocompromised patients. One case is presented: an HIV positive, 38 year old male patient, infected with P. jirovecii and apparently infected with Mycobacterium tuberculosis since 2009. He was treated with antibiotic therapy for pneumocystosis and antituberculosis (TB) therapy, which achieved a partial improvement. In 2012, the patient underwent a culture test and new anti TB treatment. Upon suspicion of a drug resistant TB strain, it was recommended to perform the mycobacterial identification. The culture test was positive and the genotypic result was positive for MAC. The first case of an HIVIAIDS patient with MAC lung infection in Peru is reported, as well as a brief review of the epidemiological, clinical and treatment aspects to the case.
\end{abstract}

Key words: Mycobacterium avium complex; HIV Infections; Respiratory tract infections (source: MeSH NLM)

\section{INTRODUCCIÓN}

El complejo Mycobacterium avium se formas por la presencia de dos especies de micobacterias: $M$. avium y $M$. intracellulare, ambas especies son difíciles de diferenciar $y$, por ello, se les denomina conjuntamente con el nombre de complejo Mycobacterium avium (MAC) ${ }^{(1,2)}$. Las infecciones por micobacterias no tuberculosas (MNT) no constituyen enfermedades notificables, por ende, es difícil realizarles un seguimiento epidemiológico. Sin embargo, la prevalencia de infecciones por micobacterias no tuberculosas, especialmente las infecciones pulmonares, han aumentado en las últimas décadas, siendo MAC el causante de la mayoría de infecciones por MNT en el mundo ${ }^{(3,4)}$.

En el Perú, durante los años 1999 al 2001 se realizó un seguimiento microbiológico a los pacientes con coinfección VIH y tuberculosis (TB) para determinar la frecuencia de Mycobacterium tuberculosis y especies de MNT, los resultados demostraron una frecuencia de $97 \%$ de M. tuberculosis y $3 \%$ de MNT. En el año 2000 se reportó un caso de duodenitis por MAC en un paciente con VIH en estadio SIDA ${ }^{(2,5)}$.

\footnotetext{
Facultad de Medicina, Universidad Peruana Cayetano Heredia. Lima, Perú

Hospital Nacional Cayetano Heredia. Lima, Perú.

Instituto Nacional de Salud. Lima, Perú

Estudiante de Medicina, ${ }^{\mathrm{b}}$ médico infectólogo, ${ }^{\mathrm{c}}$ biólogo

Recibido: 03-09-13 Aprobado: 11-12-13
}

Citar como: Carrasco J, Soto L, Samalvides F, Asencios L, Quispe N, Valencia E. Infección pulmonar por Mycobacterium avium en paciente VIH/SIDA: primer reporte en Perú. Rev Peru Med Exp Salud Publica. 2014;31(1):156-9. 
El complejo Mycobacterium avium-intracellulare está formado por organismos intracelulares obligados, que habitan principalmente en fuentes naturales como suelos y fuentes de agua. A diferencia de M. tuberculosis, MAC no causa infección latente (1). Estos patógenos son capaces de producir enfermedad tanto en pacientes inmunocompetentes como en pacientes inmunocomprometidos ${ }^{(1,2,4,5)}$. En los pacientes inmunocompetentes usualmente causan compromiso de tipo focal causando adenitis cervical o compromiso pulmonar; siendo el perfil epidemiológico una paciente mujer de edad media o avanzada o un paciente con compromiso pulmonar crónico ${ }^{(1,6)}$. En pacientes inmunocomprometidos por diferentes causas tiende a causar enfermedad diseminada $(15-40 \%)^{(2)}$.

En este reporte presentamos el primer caso en el Perú de un paciente $\mathrm{VIH} / \mathrm{SIDA}$ con infección por MAC en los pulmones.

\section{REPORTE DE CASO}

Varón de 38 años de edad, natural de la ciudad de Lima, diagnosticado como paciente VIH positivo desde diciembre de 2008. Acude al Hospital Nacional Cayetano Heredia en enero de 2009 y describe persistentes síntomas respiratorios caracterizados por tos seca sin hemoptisis, asociado a dolor abdominal y significativa pérdida de peso (12 kg en 2 meses). Hasta ese momento el paciente no había recibido tratamiento antirretroviral (TAR). Al examen físico presentó frecuencia cardíaca de 110 latidos $/ \mathrm{min}$, frecuencia respiratoria de 32 respiraciones/min, presión arterial de $80 / 50 \mathrm{mmHg}$, con $94 \%$ de saturación de $\mathrm{O}_{2}$ a $\mathrm{fiO}_{2}$ de 0,3 y temperatura mantenida de $37,5{ }^{\circ} \mathrm{C}$. En aparato respiratorio se auscultaban subcrépitos difusos a predominio de bases, sibilantes respiratorios y tiraje supraclavicular. El resto del examen sin mayores alteraciones.

Los hallazgos de laboratorio más importantes fueron: CD4: 18 células/mL y carga viral (CV): 336035 copias $/ \mathrm{mL}$. La radiografía de tórax mostró un patrón retículo nodular y alveolar bilateral, así como bronquiectasias en lóbulo superior derecho. Se le realizó tres muestras de esputo BAAR, las cuales fueron negativas, por lo que se le inicia terapia antibiótica para $P$. jirovecii por sospecha clínica y neumonía bacteriana. Es dado de alta con el diagnóstico de neumonía por $P$. jirovecii con aparente mejoría.

Tres semanas después el paciente regresa nuevamente al hospital por persistencia de sintomatología respiratoria, tos persistente, y sensación de alza térmica; la radiografía de tórax mostró una cavitación en 1/3 medio de hemitórax derecho y un patrón intersticial bilateral, por

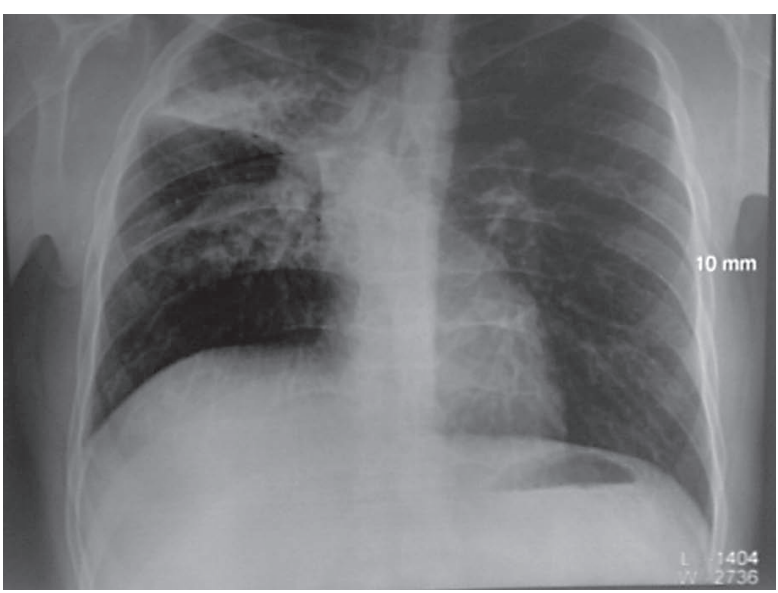

Figura 1. Radiografía de tórax

lo que se le recomienda realizar nuevamente muestra de esputo BAAR el cual resultó positivo, por ello se inicia tratamiento antituberculosis Esquema II (Esquema I + estreptomicina). Es dado de alta del programa de control de TB en noviembre de 2009.

Durante el año 2010 el paciente persistió con tos y sibilancias, es manejado con tratamiento de macrólidos obteniendo mejoría parcial.

En enero de 2011 acudió nuevamente a nuestra institución hospitalaria por mantener cuadro clínico de tres semanas con tos y expectoración. Nuevamente se le realizó una toma de muestra de esputo BAAR que fue negativo. En enero de 2012 acude nuevamente a consultorio con un resultado de BK positivo al examen por cultivo, y una radiografía de tórax que mostraba cavitación en $1 / 3$ medio de hemitórax derecho y un patrón intersticial (Figura 1), por lo cual se le indica nuevamente terapia antituberculosa Esquema I que incluye los siguientes fármacos: isoniacida $(H)$, rifampicina $(R)$, pirazinamida $(Z)$, etambutol (E) (2RHZEI4R2H2). Enviándose el cultivo obtenido a evaluar para descartar posibilidad de TB multidrogorresistente.

En septiembre de 2012, se le realizó una genotipificación, presentaba en ese momento un recuento de CD4 de 283 células $/ \mathrm{mL}$ y CV indetectable. Se realizó el protocolo de HAIN GenoType Mycobacterium /CM (Figura 2).

El resultado de la genotipificación, realizada por el Instituto Nacional de Salud en Lima Perú, fue positivo para Mycobacterium avium. Se inició tratamiento con etambutol, rifampicina, claritromicina y amikacina, tratamiento que se mantuvo hasta el momento del reporte de caso. 


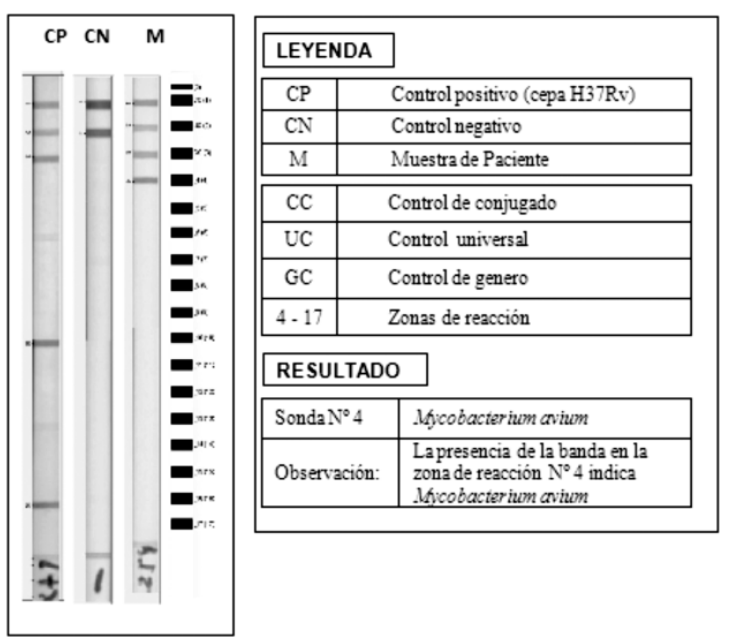

Figura 2. Sonda N. ${ }^{\circ}$ presente: Mycobacterium avium

\section{DISCUSIÓN}

Epidemiológicamente, la infección por MAC es más común en países desarrollados que en países en desarrollo. Esto encuentra una explicación en el hecho que pudiera existir una inmunidad cruzada entre $M$. tuberculosis, especie más común en países en vía de desarrollo y MAC ${ }^{(6,13)}$.

El ingreso de MAC al organismo es a través del aparato gastrointestinal o de la mucosa respiratoria. Se conoce que MAC causa tres formas de enfermedad: enfermedad pulmonaren inmunocompetentes, linfadenitis y enfermedad diseminada en inmunosuprimidos. El compromiso pulmonar se da sobre todo en inmunocompetentes con daño pulmonar previo. La enfermedad se caracteriza por tos con expectoración, pérdida de peso, fiebre, letargia y sudoración nocturna ${ }^{(1,7,12)}$.

Otras formas de presentación más inusuales de compromiso pulmonar en inmunocompetentes son el síndrome de Lady Windermere (compromiso del lóbulo medio o del lóbulo de la língula) en mujeres ancianas que no tienen enfermedad pulmonar previa y voluntariamente suprimen la tos mediante antitusígenos ${ }^{(8)}$ y un síndrome conocido como hot tub lung que es una reacción de hipersensibilidad por inhalación de MAC en usuarios de tinas de hidromasaje ${ }^{(10)}$.

La enfermedad diseminada ocurre sobre todo en pacientes con valores de CD4 menores a $50 \mathrm{cel} / \mathrm{mL}$, afectando sobre todo el sistema retículo-endotelial y el aparato gastrointestinal, en la mayoría de casos. Sin embargo, se han descrito casos de enfermedad localizada en estos pacientes ${ }^{(7)}$. En pacientes en estadio SIDA con CD4 100$250 \mathrm{cel} / \mathrm{mL}$, la diseminación puede ser contenida y generar una infección localizada en el ámbito pulmonar, ganglionar y raramente gastrointestinal y cutánea ${ }^{(1,10)}$. En el caso de nuestro paciente, comenzó con una enfermedad pulmonar, atribuida en ese momento a $P$. jirovecii debido a la mejoría parcial con tratamiento específico, y compromiso gastrointestinal cuya etiología no logró ser determinada en ese momento. El paciente presentó en ese entonces un valor de CD4 de $18 \mathrm{cel} / \mathrm{mL}$, lo cual es compatible con una enfermedad diseminada que podría explicar el compromiso pulmonar y gastrointestinal. Posteriormente, con el inicio de TAR, sus valores de CD4 se elevaron hasta $283 \mathrm{cel} / \mathrm{mL}$ lo cual permitiría localizar la enfermedad a nivel pulmonar en este caso. El tratamiento antituberculoso incluye drogas como rifampicina y etambutol que son utilizadas en el tratamiento de MAC, sin embargo, debe asociarse a otras drogas como los macrólidos para poder tratar de manera efectiva las infecciones por MAC. El uso de rifampicina y etambutol contribuyeron probablemente al control de la enfermedad pero no logró curarla y, por ello, presentaba cuadros recurrentes de sintomatología respiratoria con el cortejo sintomático ya descrito.

La linfadenitis por MAC ha sido descrita también en niños en los que compromete, sobre todo, los ganglios de la cadena cervical, submandibulares, y submaxilares. Los ganglios resuelven espontáneamente; sin embargo, algunos pueden llegar a caseificarse y fistulizar (11).

En general, la infección por MAC es tratada utilizando combinaciones de tres a cuatro antimicrobianos por al menos 12 meses. Las drogas de primera línea incluyen macrólidos como la claritromicina, la azitromicina, el etambutol y rifampicinas como el rifabutin y la rifampicina. Los aminoglucósidos como la estreptomicina y la amikacina son utilizados en pacientes con lesiones cavitarias ${ }^{(14)}$. En nuestro caso, el paciente fue tratado con una combinación de cuatro drogas que incluían etambutol, rifampicina, claritromicina y amikacina ya que presentaba una lesión cavitaria en el pulmón.

Debemos recalcar que es necesario contar con técnicas de laboratorio en los hospitales para lograr identificar el germen causante de una enfermedad infecciosa. Puesto que a pesar de las sospechas diagnósticas podríamos no estar diagnosticando enfermedades ya presentes en nuestro medio y exponer a los pacientes a tratamientos innecesarios con altas tasas de reacciones adversas a los fármacos.

Se reporta el primer caso en el Perú de infección por Mycobacterium avium en un paciente en estadio SIDA. Esta especie micobacteriana ha sido reconocida como un patógeno infrecuente en nuestro medio y ni siquiera ha sido considerada como posibilidad diagnóstica. Su presencia debe alertarnos para ser considerado como 
diagnóstico diferencial en pacientes inmunosuprimidos con sintomatología pulmonar, sin diagnóstico etiológico y que no responde a terapia convencional.

Fuentes de financiamiento: autofinanciado.

Conflictos de interés: los autores declaran no tener conflictos de interés.
Contribuciones de autoría: JC participo en la concepción del artículo, recolección de datos y redacción. LS ha participado en la concepción del artículo, recolección de datos y revisión final. FS ha participado en la revisión crítica del artículo. LA participó en el aislamiento y descripción de las técnicas utilizadas en el diagnóstico. NQ participó en el aislamiento y descripción de las técnicas utilizadas en el diagnóstico. EV participó en el aislamiento y descripción de las técnicas utilizadas en el diagnóstico.

\section{REFERENCIAS BIBLIOGRÁFICAS}

1. Aris F, Naim C, Bessissow T, Amre $\mathrm{R}$, Artho GP. AIRP best cases in radiologic-pathologic correlation: Mycobacterium avium-intracellulare complex enteritis. Radiographics. 2011;31(3):825-30. doi: 10.1148/ rg.313105171.

2. Ruiz J, Vargas G, Vivar A, Sánchez E, Nava E. Duodenitis por Mycobactreium avium intracellular en un paciente con Sindrome de Inmuno Deficiencia Adquirida (SIDA). Rev Gastroenterol Peru. 2000;20(1):76-9.

3. Kendall BA, Winthrop KL. Update on the epidemiology of pulmonary nontuberculous mycobacterial infections. Semin Respir Crit Care Med. 2013;34(1):87-94. doi: 10.1055/ s-0033-1333567.

4. Simons $S$, van Ingen J, Hsueh PR, Van Hung N, Dekhuijzen PN, Boeree MJ, et al. Nontuberculous mycobacteria in respiratory tract infections, eastern Asia. Emerg Infect Dis. 2011;17(3):343-9. doi: 10.3201/eid1703.100604.

5. Quispe N, Asencios L, Vásquez L, Leo E, Lecca L, Llanos-Zavalaga F. Detección de micobacterias tuberculosas y no tuberculosas en pacientes VIH-TB, 1999-2001 [resumen]. Rev Peru Med Exp Salud Publica. 2002;19(Supl):S6.

6. Horsburgh CR Jr, Hanson DL, Jones JL, Thompson SE 3rd. Protection from Mycobacterium avium compplex disease in human immunodeficiency virus-infected persons with a history of tuberculosis. J Infect Dis. 1996;174(6):1212-7.

7. Hibiya K, Tateyama M, Niimi M, Teruya H, Karimata Y, Hirai J, et al. Acquired immune-deficiency syndrome with focal onset of Mycobacterium avium infection displaying a histological/genetic pattern of disseminated mycobacteria. Intern Med. 2012;51(21):3089-94.

8. Dhillon SS, Watanakunakorn C. Lady Windermere syndrome: middle lobe bronchiectasis and Mycobacterium avium complex infection due to voluntary cough suppression. Clin Infect Dis. 2000;30(3):572-5.

9. Hartman TE, Jensen E, Tazelaar HD, Hanak V, Ryu JH. CT findings of granulomatous pneumonitis secondary to Mycobacterium avium-intracellulare inhalation: "hot tub lung". AJR Am J Roentgenol. 2007;188(4):1050-3.

10. Kemper CA, Deresinski SC. Mycobacterium avium complex infection in AIDS. AIDS Clin Rev. 1995-1996:153-228.

11. Flint D, Mahadevan M, Barber C, Grayson D, Small R. Cervical lymphadenitis due to non-tuberculous mycobacteria: surgical treatment and review. Int J Pediatr Otorhinolaryngol. 2000;53(3):187-94.

12. Reich JM, Johnson RE. Mycobacterium avium complex pulmonary disease presenting as an isolated lingular or middle lobe pattern. The Lady Windermere syndrome. Chest. 1992;101(6):1605-9.

13. Rubio R, Moreno S, Pulido F et al. Disseminated Mycobacterium avium complex disease in HIV.infected patients with previous tuberculosis: A case control study. 37th Intersticience Conference on Antimicrobial Agents and Chemotherapy. Toronto, Canadá; 1997.

14. Kasperbauer SH, Daley CL. Diagnosis and treatment of infections due to Mycobacterium avium complex. Semin Respir Crit Care Med. 2008;29(5):56976. doi: $10.1055 / \mathrm{s}-0028-1085708$.

Correspondencia: Leslie Soto Arquiñigo Dirección: Residencial Santa Cruz, block "N". Departamento 105. San Isidro Teléfono: 994601307

Correoelectrónico:leslie.soto@upch.pe 